\title{
Reduction of Residual Stress for High-Strength Low-Alloy Steel Strip Based on Finite Element Analysis
}

\author{
Zengshuai Qiu $\mathbb{D}^{1},{ }^{1}$ Anrui He, ${ }^{1}$ Jian Shao, ${ }^{1}$ and Xiaoming Xia ${ }^{2}$ \\ ${ }^{1}$ National Engineering Research Center for Advanced Rolling, University of Science and Technology Beijing, Beijing 100083, China \\ ${ }^{2}$ Baosteel Shanghai Meishan Iron \& Steel Co. Ltd., Nanjing 210039, China \\ Correspondence should be addressed to Zengshuai Qiu; ted_qiu_ustb@163.com
}

Received 4 December 2016; Revised 30 April 2017; Accepted 2 August 2017; Published 30 January 2018

Academic Editor: Luigi Nicolais

Copyright ( 12018 Zengshuai Qiu et al. This is an open access article distributed under the Creative Commons Attribution License, which permits unrestricted use, distribution, and reproduction in any medium, provided the original work is properly cited.

Intensive cooling technology is widely utilized in the production of high-strength hot-rolled steel strip. However, intensive cooling at high cooling rate may cause stress heterogeneity on a steel strip, which further generates great residual stress and influences steel strip shape. In this study, a three-dimensional finite element (FE) model of high-strength low-alloy steel strip on the run-out table coupled with heat transfer, phase transformation, and strain/stress is developed by ABAQUS software. To enhance modeling precision, several experiments are conducted, such as uniaxial tensile test at multiple temperatures, dynamic continuous cooling transformation, and scanning electron microscopy, to determine the material properties and boundary conditions of the FE model. Four new models are established based on this model to reduce the residual stress of strip by modifying the initial and boundary conditions. Results show that reducing the initial transverse temperature difference is the most effective in reducing residual stress, followed by sparse cooling, edge masking, and posterior cooling.

\section{Introduction}

With the development of the iron-steel industry technology, fine-grain strengthening mechanism is extensively applied in the production of a hot-rolled steel strip. This approach can improve the bending strength and toughness of the steel [1]. The traditional method to refine grains is doping alloying elements, such as $\mathrm{Ti}$ and $\mathrm{Nb}$, thus increasing production cost [2]. Alternatively, accelerated cooling technology has been widely applied in recent years. Two modes can be applied to achieve high cooling rate: by increasing the density of cooling nozzles or by increasing cooling water pressure. With rapid cooling, the temperature of the strips quickly drops below the phase transformation temperature, thereby inducing early phase transformation. This condition decreases the size of austenite grains, whereas the ferrite grains are refined despite the little consumption of alloying elements $[3,4]$. Furthermore, cooling the plate evenly is difficult because of the large flow of cooling water. Residual stress is then generated by nonuniform cooling, which influences the shape of the strips. Most notably, the shape of high-strength steel strips is more difficult to correct after cooling to room temperature than that of low-strength steels. Therefore, reducing the residual stress of steel strips on the run-out table (ROT) is important.

Several studies on the cooling process of steel strips have been reported. Kumar et al. [5] developed a model for the cooling process on the ROT of hot strip mills. The suitability of different numerical methods in solving the proposed model equation from the point of view of accuracy was investigated. The computation time was also studied, and parallel solutions for the model equation were proposed. Prieto et al. [6] developed a thermal model for the accelerated cooling on the ROT to predict the coiling temperature. The cooling process is simulated using a piece of hot strip, which is subsequently subjected to heat transfer mechanisms including conduction, convection, and radiation. Han and Park [7] developed a mathematical model considering asymmetric cooling in the thickness direction of the strip on the ROT. A finite element (FE) method is applied coupled with thermodynamic and kinetic analyses. The cooling and phase transformation behavior of the steel strip were analyzed. 
Hrabovský et al. [8] described the deformation process of a hot steel plate during the cooling process through experimental and numerical studies. Results showed that temperature distribution has the largest impact on the deformation of a strip. Wang et al. [9] established a FE model to analyze the thermal stresses during the cooling of hot-rolled strip on the ROT using the ABAQUS FE program. The results demonstrated that temperature drop within the strip edge region resulted in the development of edge waviness. Meanwhile, Milenin et al. [10] developed a model to analyze residual stress in hot-rolled sheets based on the elastic-plastic material model and the factors of the nonuniform distribution of elasticplastic deformations and unloading of the sheet material. Phase transformation and relaxation of the stress were taken into account. Cho et al. [11] developed a three-dimensional numerical model to predict the edge wave behavior of hotrolled steel strip on the ROT based on the FE method. The effect of the edge mask width and the checkers on the edge wave is examined through a series of simulations. Liu et al. [12] designed and constructed a full-scale pilot ROT facility to investigate heat transfer of steel plates under a water jet impingement. Thus, a two-dimensional FE method based on the transient inverse heat conduction model was developed. Heat fluxes and heat transfer coefficients along the impinging surface under various cooling conditions are calculated based on the model. Chester et al. [13] conducted experimental measurements in conjunction with an inverse heat conduction model to quantify boiling characteristics, as well as heat extraction histories for the different nozzle inclination angles and flow rates. Results showed that the degree of asymmetry of the cooled region on the surface of the sample increases with increasing nozzle inclination angle, whereas the overall rate of heat extraction decreases.

In this paper, four methods for reducing the residual stress of a steel strip are presented. These methods include edge masking (EM), sparse cooling (SC), posterior cooling (PC), and homogenizing the temperature of the strip. A three-dimensional FE model of steel strips during the cooling process is developed coupled with heat transfer, phase transformation, and strain/stress analysis. The model is corrected and tested with several experiments and tests and named as basic model (BM). Several new models for the four methods are established based on the BM by modifying the initial and boundary conditions.

\section{Materials and Methods}

2.1. Materials. The high-strength steel strip was produced by Meishan Iron \& Steel Co. (Nanjing, Jiangsu Province, China), and it is named BS700MC. A handheld infrared thermal camera (InfraTec, VCb) is used to measure the temperature of strips. An electronic tensile testing machine (SANS, CMT7000) is used to obtain the stress-strain curves. A Gleeble-3500 experiment machine is used to procure the CCT curves. Scanning electron microscopy (SEM, Quanta FEG 450) is used to observe the microstructure. An X-ray diffraction $(\mathrm{X}-350 \mathrm{~A})$ is used to test the residual stress.
TABLE 1: Chemical composition of the BS700MC steel (wt.\%).

\begin{tabular}{lcccccc}
\hline $\mathrm{C}$ & $\mathrm{Mn}$ & $\mathrm{Nb}$ & $\mathrm{Ti}$ & $\mathrm{Ni}$ & $\mathrm{Cr}$ & $\mathrm{Mo}$ \\
\hline 0.06 & 1.84 & 0.06 & 0.09 & 0.08 & 0.02 & 0.17 \\
\hline
\end{tabular}

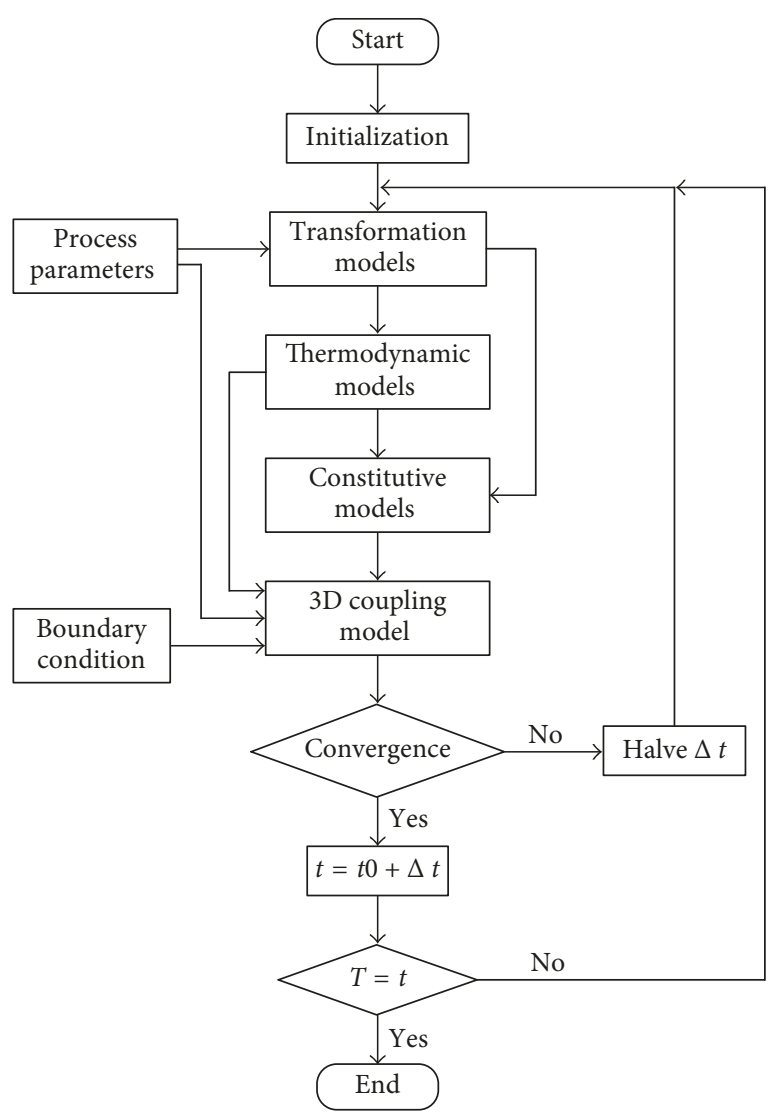

FIgURE 1: Flow chart of the FE model.

The chemical composition of BS700MC is shown in Table 1.

2.2. The Finite Element Model. The dynamic-implicit method is used to establish the FE model based on ABAQUS. User subroutines from ABAQUS are written to introduce the influence of phase transformation to the FE model. The finite element model includes a 3D-coupled temperaturedisplacement model, a phase transformation model, and a constitutive model. The relationships among each model in the calculation process are shown in Figure 1.

The length of the ROT is $145.8 \mathrm{~m}$, which is from the last stand of the finishing mill to the coiling machine. The simulation schedule will be too large if a full-length steel strip model is established. For the purpose of high calculation accuracy and low computational cost, the length of strip for the FE model is decided as $3 \mathrm{~m}$ after several tests. The size of the model is $3 \mathrm{~m} \times 1.2 \mathrm{~m} \times 0.006 \mathrm{~m}$, and the temperature on the central line is approximately from $860^{\circ} \mathrm{C}$ to $580^{\circ} \mathrm{C}$; the strip passes through the ROT at the rate of $10 \mathrm{~m} / \mathrm{s}$. 


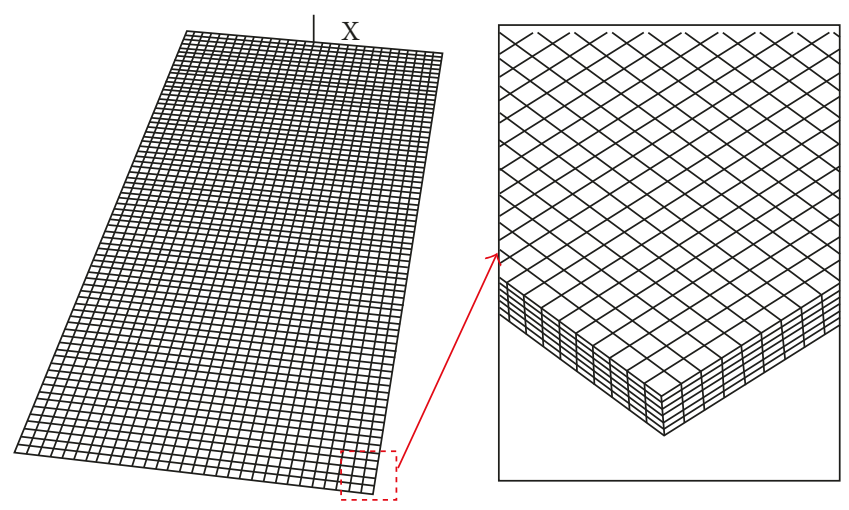

FIgURE 2: Meshing of the FE model.

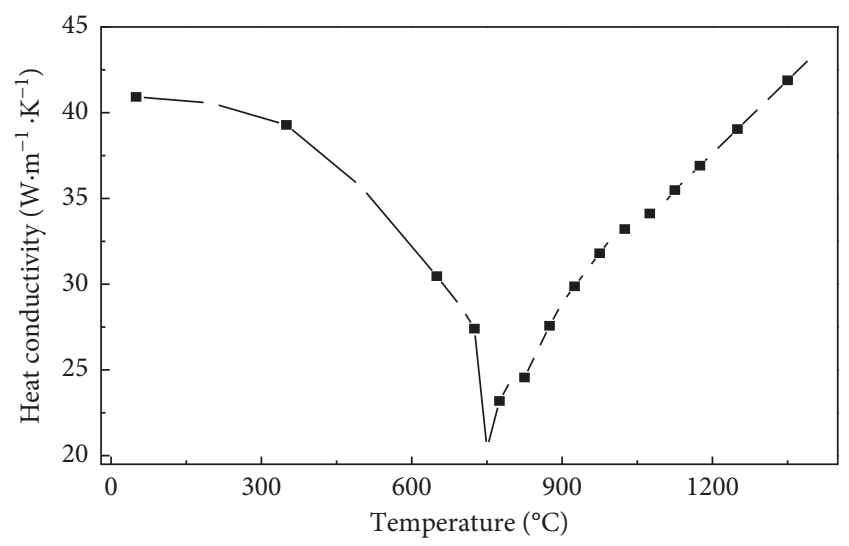

Figure 3: Heat conductivity of BS700MC.

2.2.1. Meshing of the Model. The element type of the FE model is the coupled temperature-displacement hexahedral elements, named C3D8T in ABAQUS. The size of the element is $3 \mathrm{~mm} \times 3 \mathrm{~mm} \times 1 \mathrm{~mm}$, as is shown in Figure 2 .

2.2.2. Material Properties of the Model. The material properties, which depend on temperature, play important roles on computational accuracy of the FE model. The material properties in the model are thermal physical parameters including thermal properties, such as specific heat capacity and thermal conductivity, and mechanical properties such as elastic modulus and Poisson's ratio. These properties which depend on temperature and are provided by Meishan Iron \& Steel Co. are shown in Figures 3 and 4.

Elastic and plastic parameters are also important to the FE model, as they can be approximated by stress-strain curves. The curves are based on the uniaxial tension test at various temperatures. The electronic tensile testing machine named SANS-CMT7000 is operated according to the standards of GB/T228.1-2010 [14]. The deformation temperatures of the specimen are set as $200,400,600$, and $800^{\circ} \mathrm{C}$, and the strain rate is $10^{-3} / \mathrm{s}$. During the test, three samples were tested at each temperature, and the average value from the three samples was taken as the test result. The measured true stress-strain curves are shown in Figure 5.

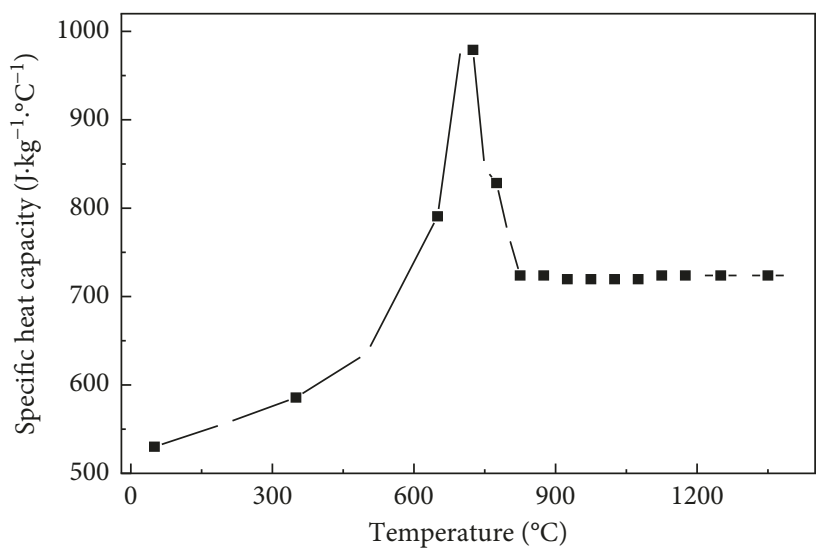

FIGURE 4: Specific heat capacity of BS700MC.

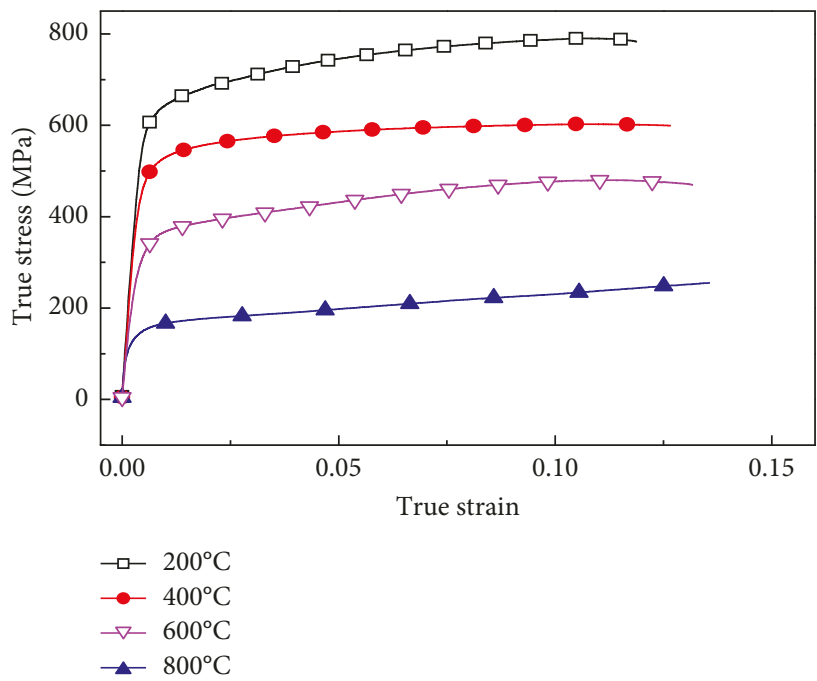

FIGURE 5: Stress-strain curve of the steel.

The curves at any temperature can be expressed by the bilinear interpolation of temperature and strain. Elastic and plastic constitutive models are established according to the true stress and strain curves under different temperatures.

The thermal expansion coefficients of different phases are as follows [15]:

$$
\begin{aligned}
& \alpha_{\mathrm{A}}=1.86 * 10^{-5}, \\
& \alpha_{\mathrm{F}}=1.14 * 10^{-5}, \\
& \alpha_{\mathrm{B}}=1.21 * 10^{-5} .
\end{aligned}
$$

According to the steel chemistry, the expansion coefficients of the transformation from austenite to other phases are as follows [16]:

$$
\begin{aligned}
\beta_{\mathrm{A} \rightarrow \mathrm{F}}=2.17 \times 10^{-3}+[ & (750-T) \times 4.06 \\
+ & \left.\left(750^{2}-T^{2}\right) \times 1.51 \times 10^{-3}\right] * 10^{-6}, \\
\beta_{\mathrm{A} \rightarrow \mathrm{B}}=4.81 \times 10^{-3}+[ & (700-T) \times 0.9 \\
+ & \left.\left(700^{2}-T^{2}\right) \times 3.3 \times 10^{-3}\right] * 10^{-6} .
\end{aligned}
$$




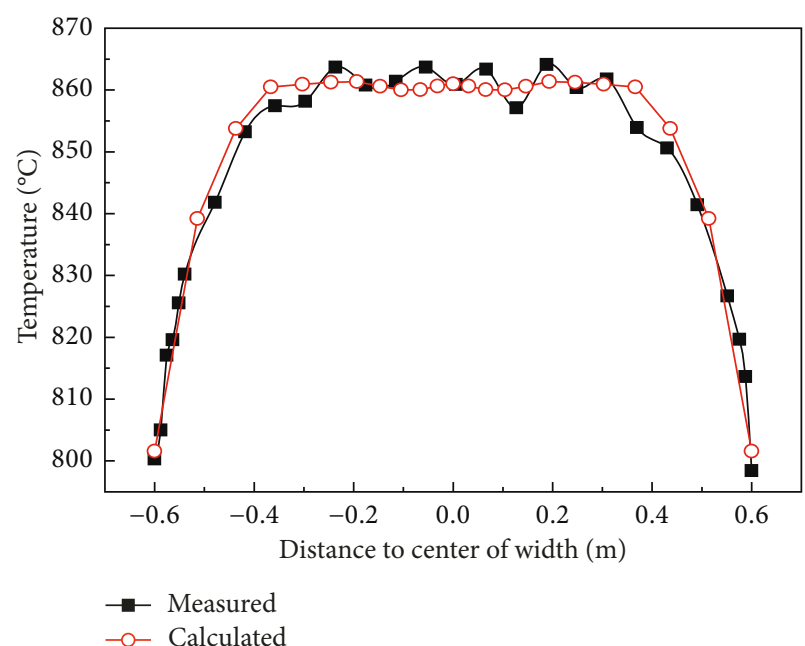

(a)

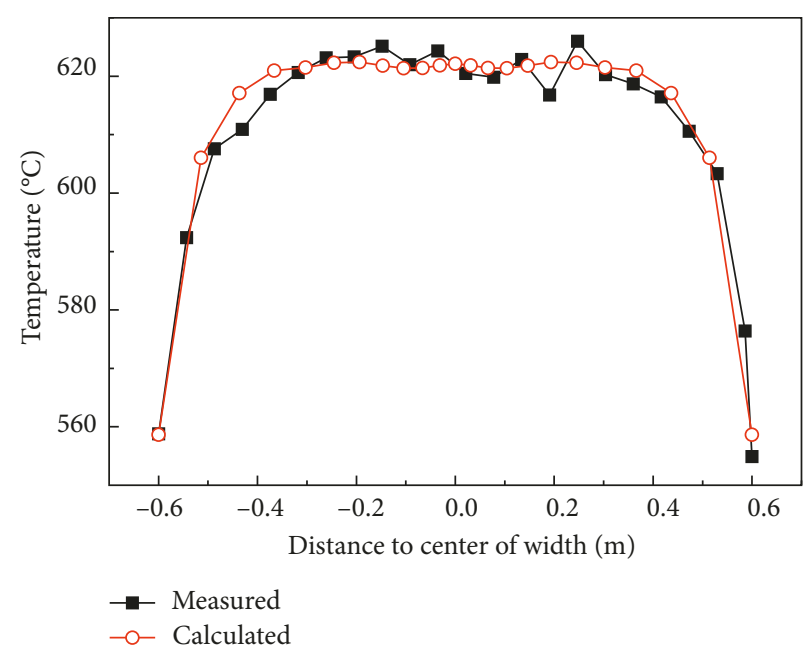

(c)

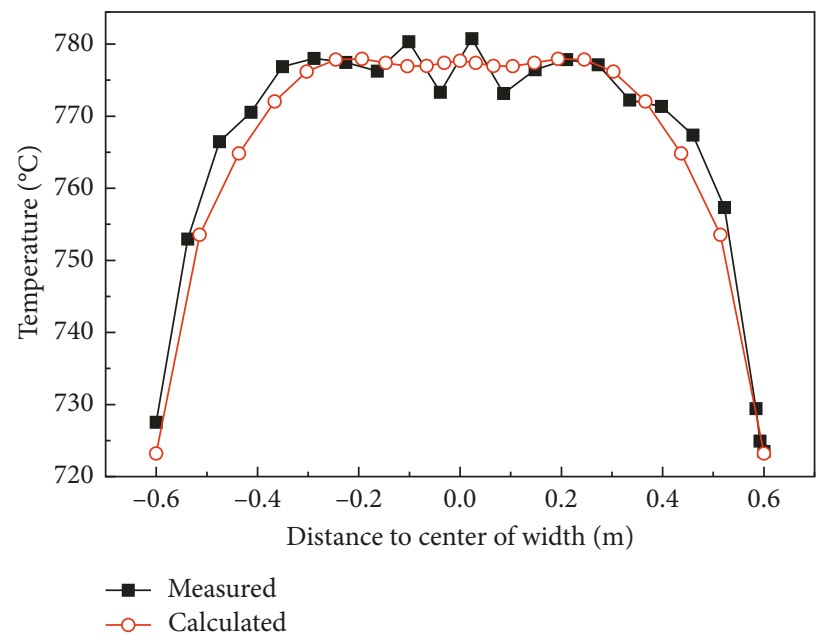

(b)

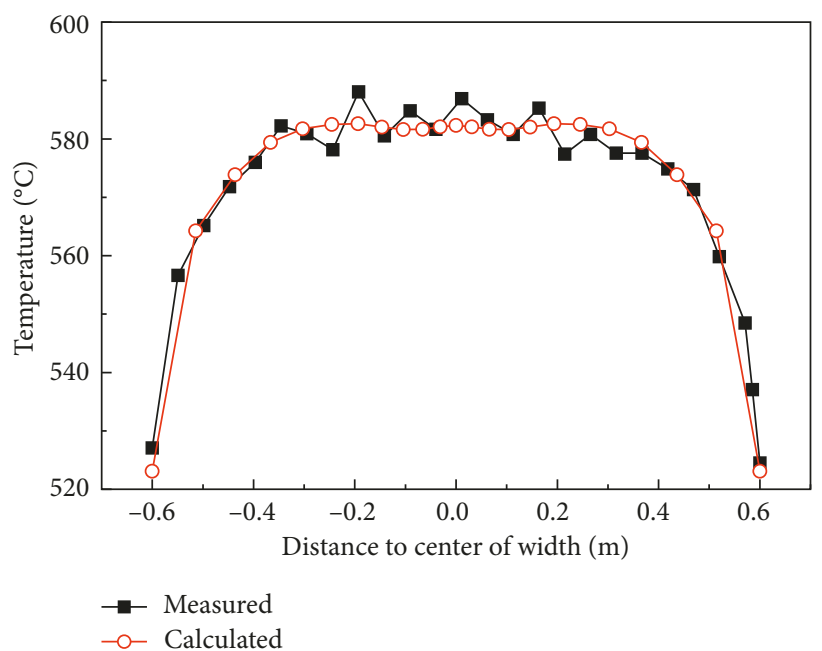

(d)

Figure 6: Temperature distribution from calculation and measurement: (a) outlet of F7; (b) front of intensive cooling zone; (c) front of trimming cooling zone; (d) before coiling machine.

The phase transformation expansion and thermal expansion are defined in the user subroutine program UEXPAN, whereas the constitutive equations are defined in the user subroutine program UMAT.

2.2.3. Initial Conditions. The initial temperature and residual stress on the strip after finishing mill have great influence on the calculation results. The initial stress affects the calculation results of stress but does not affect the evolution $[15,17,18]$. This research focuses on the effects of the evolution and the distribution of temperature on stress during the cooling process. Therefore, the initial residual stress of the strip is ignored in the BM, and the influence of initial temperature is considered.

The distribution of initial temperature along the length and thickness of the strip is uniform. The distribution of initial temperature along the width direction is shown in Figure 6(a).

2.2.4. Boundary Conditions. The boundary conditions remarkably influence the calculation results of the FE model. Thermal boundary conditions are more complex than displacement boundary conditions in the coupled FE model. The cooling strategy of the high-strength steel strips is shown in Figure 7. The cooling process of the strip includes intensive cooling, air cooling, and trimming cooling before coiling. The thermal boundary conditions are different in each cooling section.

In the intensive cooling zone and trimming cooling zone, the cooling medium is water and the mode of heat exchange between strips and outside is convection heat transfer. The convection heat transfer coefficient is 


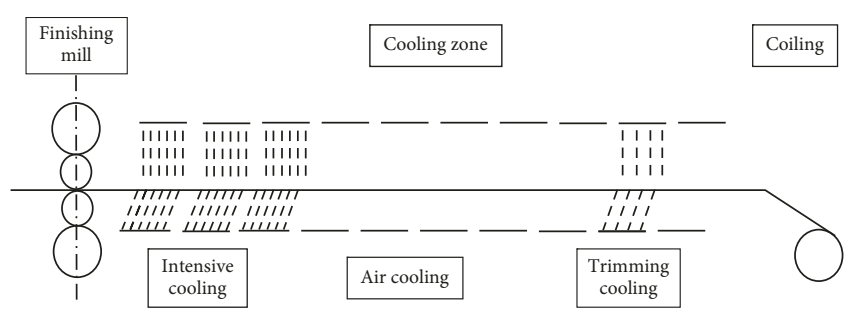

Figure 7: Cooling strategy of the high-strength steel strips.

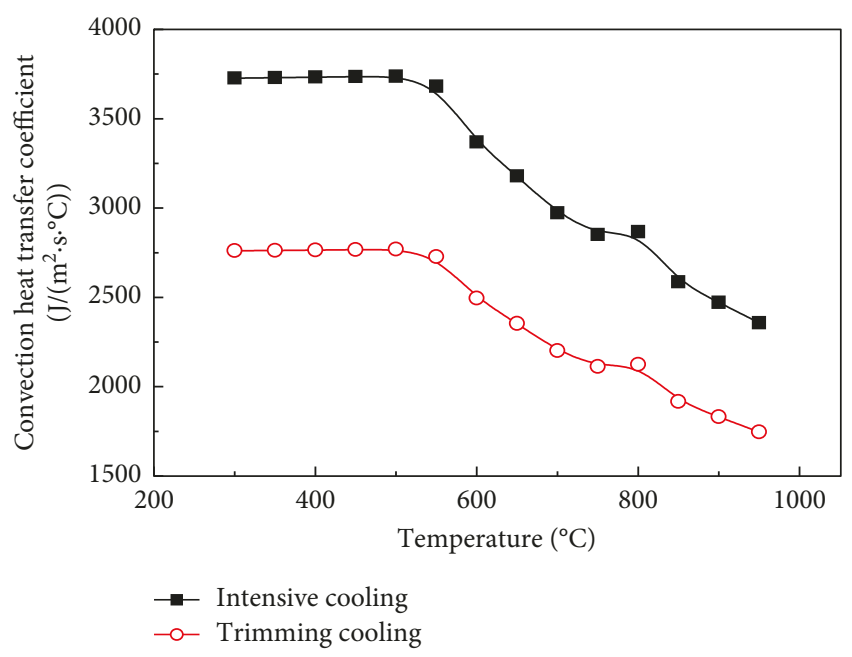

Figure 8: Heat convection coefficients of water cooling.

determined by the temperature of the strip surface and the cooling process [19], which is as follows:

$$
h_{w}^{c}=\frac{9.72 \times 10^{5} \omega^{0.355}}{T-T_{w}} \times\left[\frac{\left(2.5-1.5 \ln T_{w}\right) D}{P_{l} P_{c}}\right]^{0.645} \times 1.163 .
$$

The temperature of the strip surface has a major impact on the heat transfer efficiency of water-cooling process. When the water contacts the hot strip surface, the water boils at once. A layered vapor film is formed between cooling water and strip surface, which isolates the steel strip and cooling water. The heat transfer efficiency is reduced. According to the cooling process, the dependence of the convection heat transfer coefficient on the temperature of the strip surface is shown in Figure 8.

The modes of heat exchange of the strip during air cooling include surface radiation and convection heat transfer with air. The free convection heat transfer coefficient is less than $25 \mathrm{~J} /\left(\mathrm{m}^{2} \cdot \mathrm{s} \cdot{ }^{\circ} \mathrm{C}\right)$. The emissivity of the hot-rolled steel strip on the ROT is shown in the following equation [20]:

$$
\varepsilon=\frac{T-273}{1000}\left(0.125 \frac{T-273}{1000}-0.38\right)+1.1,
$$

where $T$ is the absolute temperature of the strip surface, ${ }^{\circ} \mathrm{C}$.

\subsubsection{Mathematical Models}

(1) Three-dimensional Thermal Model. The threedimensional heat conduction differential equation of steel strips considering latent heat due to phase transformation during the cooling process is shown in

$$
\frac{\partial}{\partial x}\left(\lambda \frac{\partial T}{\partial x}\right)+\frac{\partial}{\partial y}\left(\lambda \frac{\partial T}{\partial y}\right)+\frac{\partial}{\partial z}\left(\lambda \frac{\partial T}{\partial z}\right)+q=\rho c_{p} \frac{\partial T}{\partial t},
$$

where $q$ is the latent heat caused by phase transformation, J; $T$ is the temperature, ${ }^{\circ} \mathrm{C} ; t$ is the time, $s ; \lambda$ is the thermal conductivity, $\mathrm{W} /(\mathrm{m} \cdot \mathrm{K}) ; \rho$ is the density, $\mathrm{kg} / \mathrm{m}^{3}$; and $c_{p}$ is the specific heat, $\mathrm{J} /\left(\mathrm{kg} \cdot{ }^{\circ} \mathrm{C}\right)$.

(2) Phase Transformation Model. The equations of phase transformation of the hot-rolled low-alloy steel strip selected in this research are as follows [21]:

$$
\begin{aligned}
\frac{X}{X^{e}} & =1-\exp \left(m t^{n}\right), \\
m & =-\frac{1}{2.24}\left(\frac{2.24}{D_{\gamma}} q+0.114(\Delta \varepsilon)^{2}\right) \times(1+B(\Delta \varepsilon)) k,
\end{aligned}
$$

where $X$ is the transformation volumetric fraction; $X^{e}$ is the thermodynamic equilibrium fraction related to compositions and temperature of the steel; $t$ is the time of isothermal transformation, $s ; B, k$, and $n$ are related to the compositions and temperature of the steel; $D_{\gamma}$ is the austenite grain size, $\mu \mathrm{m}$; and $\Delta \varepsilon$ is the residual strain.

The effect of austenite grain size and residual strain on phase transformation is introduced in the equation. The process of isothermal transformation is simulated using (7) and (8). The cooling process of the hot-rolled steel strip on the ROT is continuous cooling rather than the isothermal process. The principle of superposition is introduced in this research to discrete transformation during continuous cooling into a number of isothermal transformation increments $[22,23]$. The equations of discretization method are as follows:

$$
\begin{aligned}
\frac{X_{i}}{X_{i}^{e}} & =1-\exp \left[-m_{i}\left(t^{\prime}{ }_{i}+\Delta t_{i}\right)^{n}\right], \\
t_{i}^{\prime} & =\left[-\frac{1}{m_{i}} \ln \left(1-\frac{X_{i-1}}{X_{i}^{e}}\right)\right]^{1 / n}
\end{aligned}
$$

where $\Delta t_{i}$ is the time increment of the $i$ th increment, s, and $t_{i}^{\prime}$ is the virtual time, $s$.

The phase transformation from undercooled austenite to lower energy phases will release heat, and it is considerable. The phase transformation latent heat $q$ in (2) is calculated using the following equation:

$$
q=\Delta H_{i} \frac{\Delta X_{i}}{\Delta t} \rho c_{p}
$$

where $\Delta H_{i}$ is the latent heat when the phase transformation of austenite is completed, $\Delta H_{\mathrm{F}}=7.6 \times 10^{4} \mathrm{~J} \cdot \mathrm{kg}^{-1}, \Delta H_{\mathrm{B}}=7.9 \times$ $10^{4} \mathrm{~J} \cdot \mathrm{kg}^{-1}, \Delta X_{i}$ is the transformation volumetric fraction at the $i$ th increment, and $\Delta t$ is the length of the $i$ th increment, s. 
The user subroutine USDFLD is written to introduce the transformation kinetics equation into the FE model, whereas the user subroutine HETVAL is used to introduce the latent heat due to transformation into the FE model.

(3) Constitutive Model. The strain generated in the cooling process is a result of the synthetic effect of several mechanisms, and the composition of the strain is as follows:

$$
d \varepsilon_{i j}=d \varepsilon_{i j}^{e}+d \varepsilon_{i j}^{\mathrm{th}}+d \varepsilon_{i j}^{p}+d \varepsilon_{i j}^{\mathrm{tr}}+d \varepsilon_{i j}^{\mathrm{tb}},
$$

where $d \varepsilon_{i j}^{e}, d \varepsilon_{i j}^{\text {th }}$, and $d \varepsilon_{i j}^{p}$ are the increments of elastic strain, thermal strain, and plastic strain, respectively. Meanwhile, $d \varepsilon_{i j}^{\mathrm{tr}}$ and $d \varepsilon_{i j}^{\mathrm{tb}}$ are strain increments caused by phase transformation expansion and phase transformation-induced plasticity, respectively.

The strain increment caused by phase transformationinduced plasticity is given by Han et al. [24]:

$$
d \varepsilon_{i j}^{\mathrm{tb}}=\frac{1}{3} \frac{d_{0}}{\delta} \dot{X} \frac{\sigma \varphi}{k_{B} T} c_{\nu 0} \exp \left(-\frac{Q_{f}}{k_{B} T}\right),
$$

where $d_{0}, \delta$, and $\varphi$ represent the initial grain size of the parent phase, the effective thickness of the interface, and the volume of the vacancy, respectively. The Boltzmann constant, $k_{B}$, has a value of $1.38 \times 10^{-23} \mathrm{~J} / \mathrm{K} . c_{\nu 0}$ is a dimensionless constant determined by the change in thermal entropy associated with the formation of vacancies, and $Q_{f}$ is the formation enthalpy of the vacancy at the interface. $\sigma$ and $\dot{X}$ are the applied stress and transformation rate, respectively.

The structure of the equation for stress is as follows:

$$
d \sigma_{i j}=[C]_{i j} d \varepsilon_{i j}
$$

where $[C]_{i j}$ are the components of the Jacoby matrix based on the stress-strain curves from uniaxial tensile tests at various temperatures.

The user subroutine UMAT is written to introduce the strain of phase transformation-induced plasticity into the FE model and rebuild the Jacoby matrix.

2.3. Experimental Method. The FE models in this paper are all based on the BM. It is necessary to ensure the calculating precision of the BM. Several experiments and tests are performed in this research.

2.3.1. Experiment for Temperature Field. To correct the initial temperature and boundary conditions of the FE model during the cooling process, surface temperatures of the strips in four different locations of the ROT are measured with a handheld thermal imager. The four locations include finish rolling outlet, front of the intensive cooling zone, front of the trimming cooling zone, and front of the coiling machine, as shown in Figure 7. The convective heat transfer coefficient and emissivity of different cooling zones for the FE model are obtained based on the measured temperature. The emissivity of the thermal imager must be corrected before measurement. The correction method is adjusting the emissivity of the imager until the temperature of the outlet measured with the imager is equal to the temperature measured with the multifunction

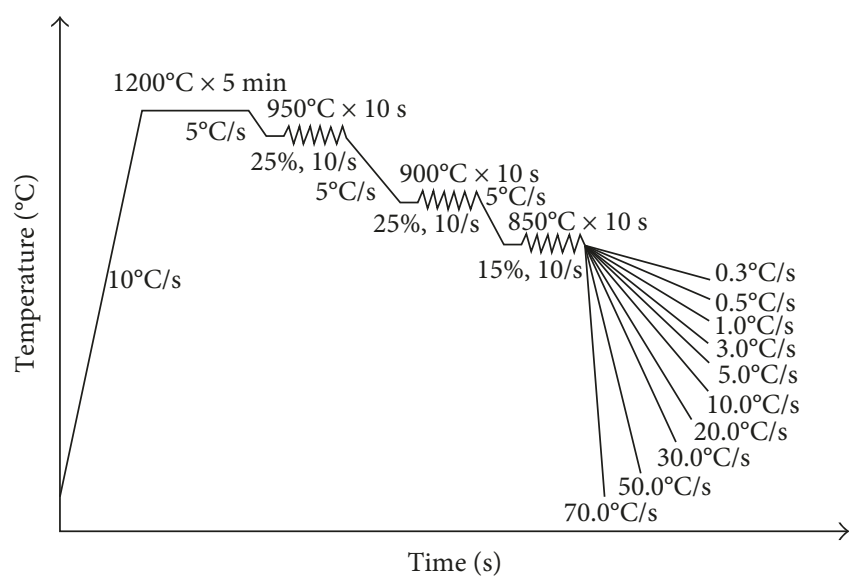

Figure 9: Dynamic CCT test procedures.

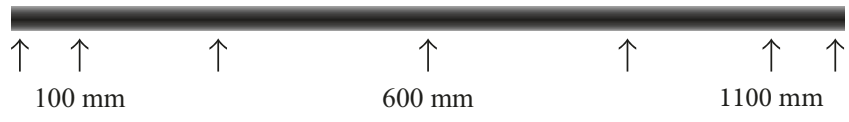

Figure 10: Sampling positions along the width of the strip.

instrument. The emissivity of the thermal imager during strip temperature measurements is 0.86 .

2.3.2. Dynamic CCT Test. The experimental procedures of dynamic continuous cooling transformation (CCT) test are shown in Figure 9. The testing equipment is Gleeble-3500. The dumbbell-shaped specimens $(\Phi 6 \mathrm{~mm} \times 15 \mathrm{~mm})$ are heated to $1200^{\circ} \mathrm{C}$ at the rate of $10^{\circ} \mathrm{C} / \mathrm{s}$, for $5 \mathrm{~min}$. They are cooled to $950^{\circ} \mathrm{C}$ at the rate of $5^{\circ} \mathrm{C} / \mathrm{s}$ for $10 \mathrm{~s}$ to eliminate the temperature gradient. The specimens are compressed at the strain rate of $10 \mathrm{~s}^{-1}$, and the strain is $25 \%$. Then, they are cooled to $900^{\circ} \mathrm{C}$ at the rate of $5^{\circ} \mathrm{C} / \mathrm{s}$ for $10 \mathrm{~s}$. Subsequently, the specimens are compressed at the strain rate of $10 \mathrm{~s}^{-1}$, and the strain is $25 \%$, which are cooled to $850^{\circ} \mathrm{C}$ at the rate of $5^{\circ} \mathrm{C} / \mathrm{s}$ for $10 \mathrm{~s}$. The specimens are then compressed at the strain rate of $10 \mathrm{~s}^{-1}$, and the strain is $15 \%$. Afterwards, the specimens are cooled into ambient temperature, and the cooling rates are $0.3,0.5,1,3,5,10,20,30,50$, and $70^{\circ} \mathrm{C} / \mathrm{s}$.

The specimens are cut into half (lengthwise) for metallographic analysis. The SEM is used to observe the microstructure of the specimens, which were cooled at different cooling rates. Moreover, the Vickers hardness tester is used to examine the Vickers hardness of the specimens. The obtained critical temperatures about the phase transformation refer to the metallography and microhardness of the steel based on the dilation curves during cooling and heating processes, such as Ac1, Ac3, Ar1, Ar3, and Ms. The starting and final temperatures of each phase in the phase transformation are solved, and the dynamic CCT curves are drawn out.

2.3.3. SEM Experiments. Samples $(6 \mathrm{~mm} \times 8 \mathrm{~mm} \times 10 \mathrm{~mm})$ from seven different positions of a hot-rolled high-strength steel strip with a width of $1200 \mathrm{~mm}$ were prepared for the 


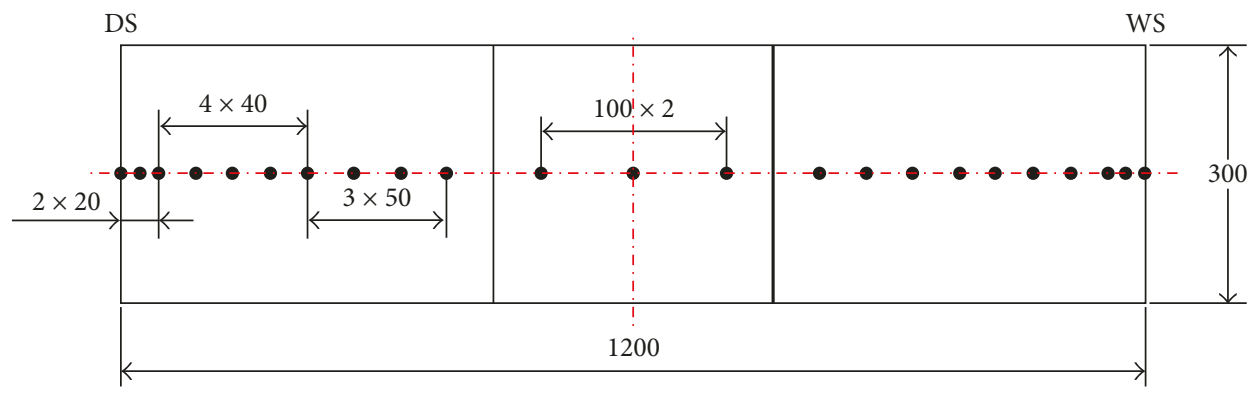

Figure 11: Positions on the width of the plate.

SEM analysis to determine the differences in microstructures. The seven positions on the width of the steel strips are shown in Figure 10.

2.3.4. Residual Stress Measurement. A piece of the highstrength steel strip is provided by Meishan Iron \& Steel Co., and its length and width are $300 \mathrm{~mm}$ and $1200 \mathrm{~mm}$, respectively. A cold-shearing machine is used to cut the strip to avoid the influence of the thermal stress on the original residual stress. The tested steel plates were cut with enough length, and the measuring points are far away from the cutting surface. An X-ray diffractometer is operated to measure the residual stress of the strip at different positions. The positions in the transverse direction of the strip are shown in Figure 11. The residual stress along the length of strip and its distribution in width determine the flatness of the strip. Therefore, the residual stress along the length is measured. Each point was tested for three times, and the average value was taken. The test error caused by the equipment was less than $5 \mathrm{MPa}$.

To avoid the influence of the surface oxide scale, the pickling and electrolytic polishing on the surface of the plate are necessary before the measurement.

\section{Results and Discussion}

3.1. Verification and Results of the Basic Model. The results of the experiments and the BM are compared in this paper to verify the precision of the BM.

\subsubsection{Temperature Field}

(1) Verification of the $B M$. The temperature results of the BM are adjusted to the temperature value measured with the thermal imager at same cooling positions. The accuracy of thermal imager temperature measurement is $\pm 2 \%$. The convective heat transfer coefficient and emissivity are then calculated. The temperature result from the BM and thermal imager is shown in Figure 6.

By comparing the results of the FE model and measurement, it can be found that the distribution and value of the results are almost consistent, and the temperature in the central strip is higher than the temperature on both edges. Figure 6 shows the accurate calculations of the initial and coil temperatures. Meanwhile, the cooling path is calculated accurately compared to the temperature measured at the four positions. The FE model for temperature has high precision.

(2) Results of the BM. Four nodes of the strip model are selected to analyze the evolution process of temperature field and phase transformation at the four typical locations. The four locations are shown in Figure 12.

As shown in Figure 12, nodes 2 and 3 are on the surface of the strip, whereas nodes 1 and 4 are in the center layer. While nodes 1 and 2 are in the middle, nodes 3 and 4 are on the edge. The cooling process of the four nodes on the ROT is shown in Figure 13.

Re-reddening at the two nodes on the surface occurred after water cooling, and it is more significant after intensive cooling. Re-reddening indicates that the temperature on strip surface rises after water cooling, wherein the color of the strip surface turned red. It is caused by the different cooling rates between the surface and inside of the hot-rolled steel strip.

The cooling processes are different between the edge and middle part of the steel strip as shown in Figure 13. The nonsynchronization cooling process on different parts of the steel strip and the uneven distribution of temperature on the steel strip caused the nonsynchronization of phase transformation and residual stress in the steel strip.

\subsubsection{Phase Transformation}

(1) Results of the BM. The results from the FE model about austenite transformation during the cooling process at the four nodes in Figure 12 are depicted in Figure 14.

As shown in Figure 14, the result of the FE model illustrates that the sequence of phase transformation starts at the four nodes in the following order: node 3, node 2 , node 4, and node 1 . The phase transformation of the nodes on surface starts earlier, because the nodes on the surface cool faster than the inside ones during intensive cooling zone, thus reaching the transformation temperature earlier. At the beginning, the velocity of phase transformation of the surface is relatively high and then changes after certain time of phase transformation. Meanwhile, the velocity of phase transformation on edges is more rapid than that of the nodes in the central section. The reason for this is that the temperature at surface and inside gradually becomes almost 


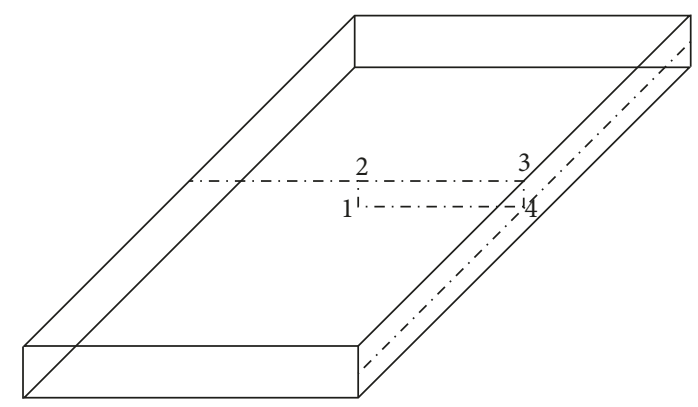

Figure 12: The four nodes.

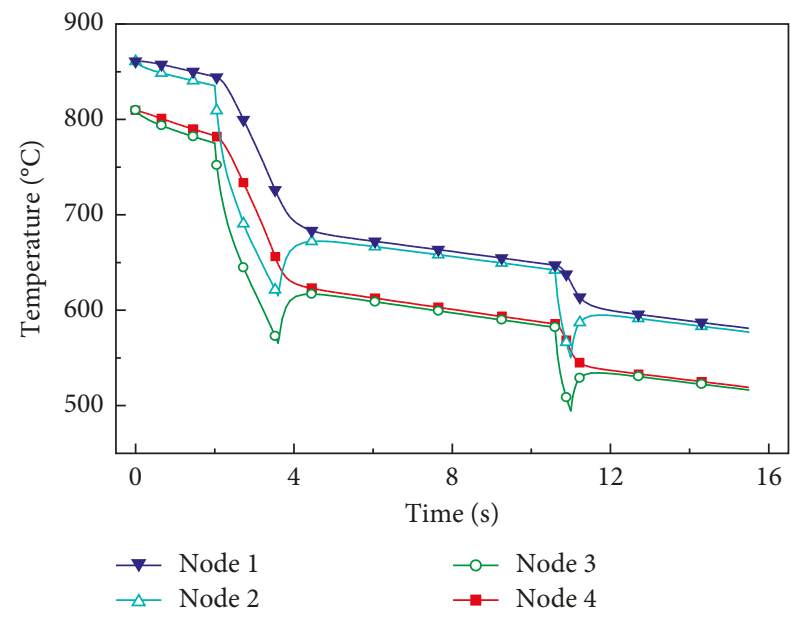

FIgURE 13: Cooling process of the four nodes.

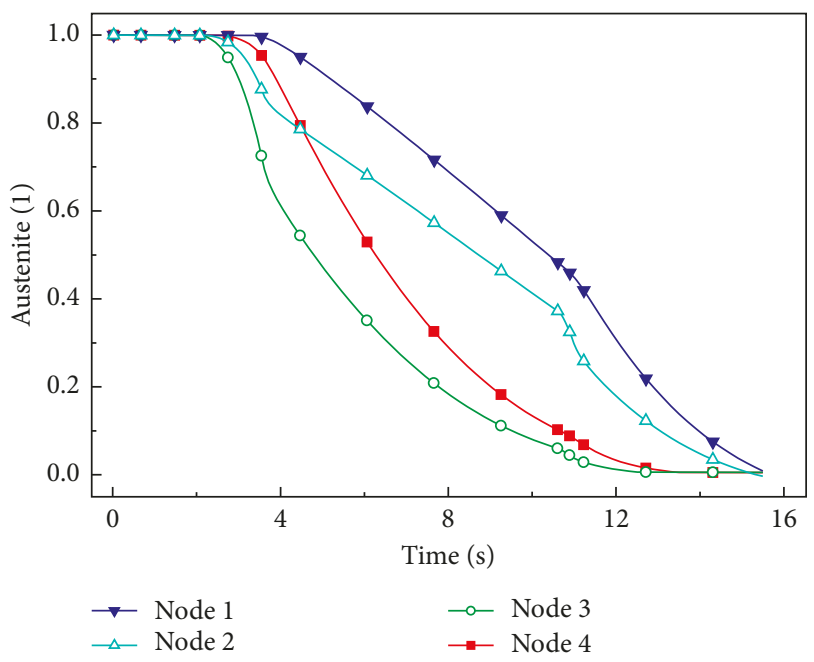

FIGURE 14: Austenite transformation.

similar, and the temperature differences mainly occur on the edges and central section of the steel strip. Most of the time, the velocity of phase transformation of the nodes on edges is faster than that in the central section. As shown in Figure 14, phase transformation of the nodes on edges stops earlier.

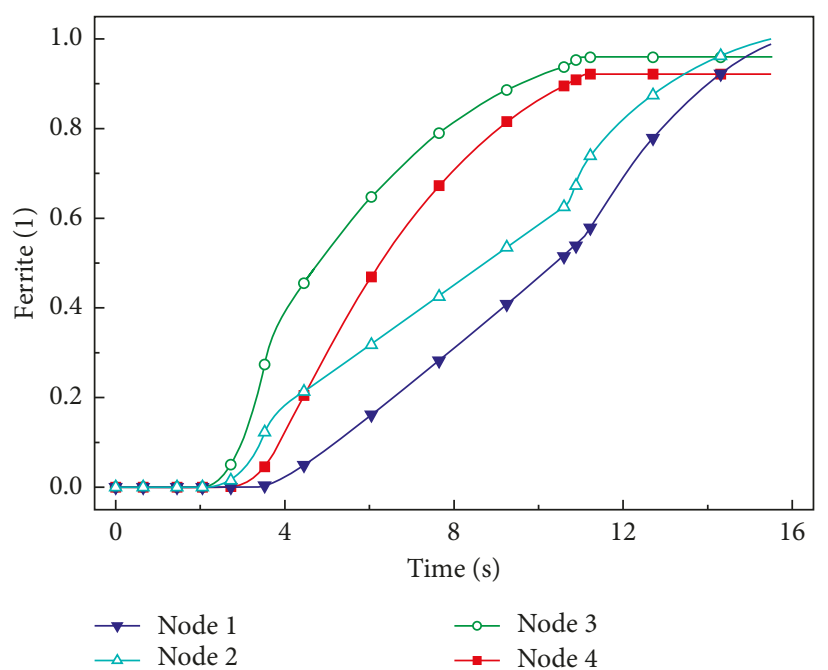

Figure 15: Transformation process of ferrite.

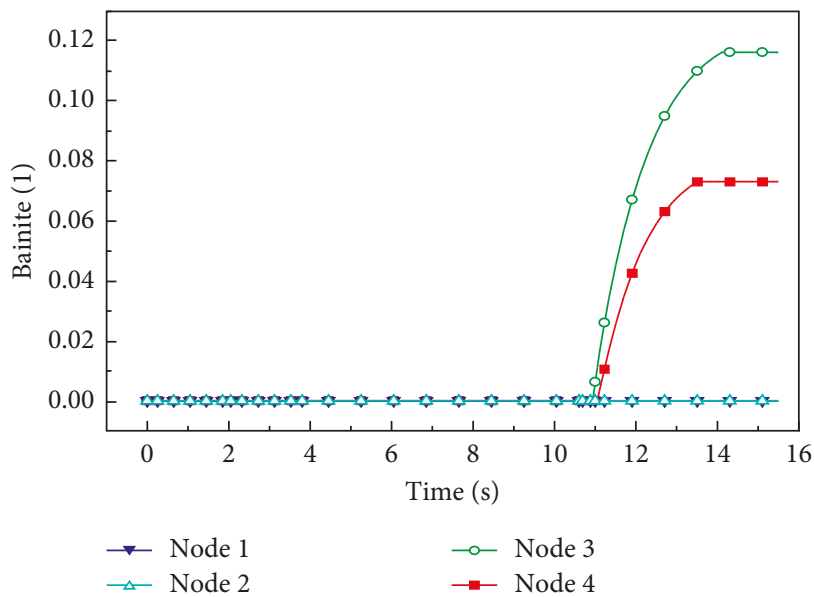

FIgURE 16: Transformation process of bainite.

The products of austenite transformation are ferrite and bainite. The transformation from austenite to ferrite is shown in Figure 15.

At the four nodes, more than $85 \%$ of austenite finally transforms to ferrite. As shown in Figures 14 and 15, ferrite generation stops earlier than austenite phase transformation at the nodes on edges; however, they are synchronous at the nodes on central section. This implies that there are other transformation products present. According to the result of the FE model, the other transformation product is bainite (Figure 16).

The transformation of bainite needs lower temperature and higher cooling rate than ferrite. Thus, the transformation of bainite occurs later than the transformation of ferrite. From the results of the FE model, little bainite is present on edges, whereas only ferrite exists on middle. The distribution of bainite on the surface of the steel strip after cooling is shown in Figure 17. 


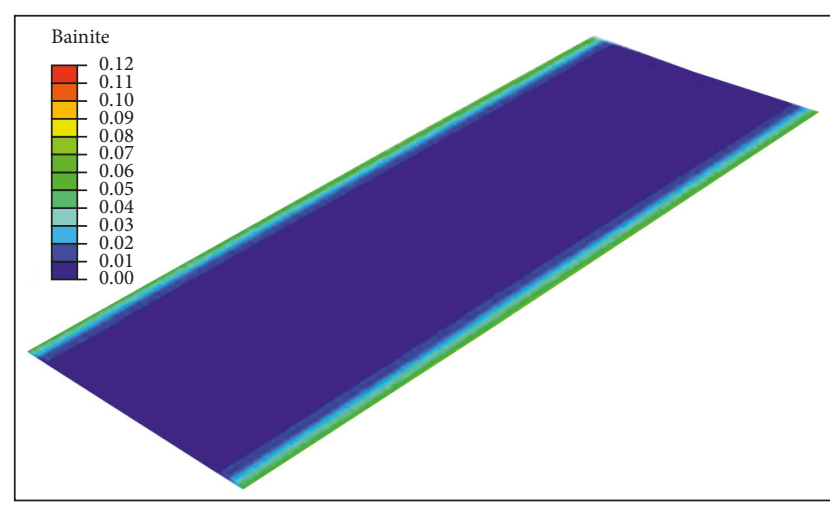

FIgURE 17: Distribution of bainite.

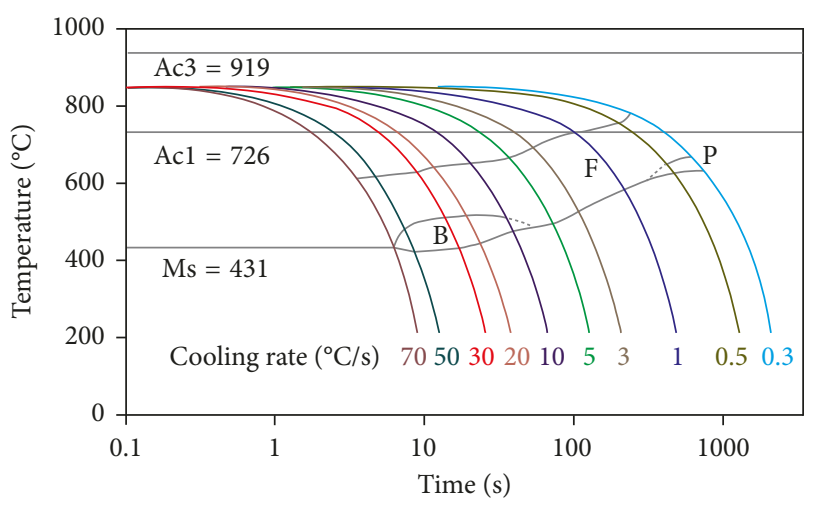

Figure 18: Dynamic CCT curves.

(2) Results of Experiments. According to dilation curves during heating and cooling processes of dynamic thermal simulation test, the dynamic CCT curves are drawn out using the thermal dilation method, as is shown in Figure 18.

Based on the dynamic CCT curves, the Ac1 for BS700MC is about $726^{\circ} \mathrm{C}$. The products of transformation are ferrite and pearlite when the cooling rate is less than $0.5^{\circ} \mathrm{C} / \mathrm{s}$. When the cooling rate of the steel is higher than $10^{\circ} \mathrm{C} / \mathrm{s}$ and the temperature is lower than $\mathrm{B}_{\mathrm{s}}$ (the starting temperature of bainite transformation), the resulting product is bainite. The transformation temperature is about $540^{\circ} \mathrm{C}$ and $431^{\circ} \mathrm{C}$ for bainite and martensite, respectively.

Several images are obtained from the SEM experiments to observe the microstructure of the steel strip provided by Meishan Iron \& Steel Co. The two images in Figure 19 are the SEM images of the specimens on the edge and middle of the steel strip corresponding to nodes 3 and 2 in Figure 12. A little amount of bainite can be found in the specimens from the edge as is shown in Figure 19(a), whereas the ferrite and cementite are found on the central part as is shown in Figure 19(b).

According to the CCT curves of BS700MC, the products of transformation during the cooling process on the ROT are ferrite and bainite under certain conditions. From the SEM images, the products on the edge of the steel strip are ferrite and a little bainite, but ferrite and cementite are on the central part. The results of these experiments are consistent with the results of the BM. In general, the BM has high precision on the calculation of phase transformation.

3.1.3. Stress Distribution. Stress in steel strips is mainly caused by the nonsynchronization of cooling and phase transformation in different parts of the strip. The expansion coefficients of phase transformation are about 200 times of thermal expansion coefficients. The nonsynchronization of phase transformation is more apparent than that of cooling. Overall, the effect of transformation is more significant on the stress during the cooling process.

The current study focuses on the stress distribution on the transverse of steel strips, which determines their flatness. The stress distribution along the blue line on the steel strip from the BM is shown in Figure 20.

The stress distribution along the line is depicted in Figure 20 , and the stress distribution is measured by X-ray diffraction, as shown in Figure 21.

While the sign of the stress on edges is negative, the sign on the central section is positive. The sign of stress represents the direction, not its intensity. Positive stress means tension, whereas negative stress means compression. The compressive stress on edges is over $200 \mathrm{MPa}$. The tension on central section is less than $50 \mathrm{MPa}$. According to the relationship between the plate shape and stress distribution, high risk of edge waves exists in such stress distribution.

As is shown in Figure 21, the results of the BM are consistent with the measurement. The BM has high precision on stress calculation.

3.2. Analysis of Reducing Residual Stress. Based on the BM, several FE models are established to analyze the effect of the four methods in reducing residual stress. Several methods are considered to determine the best conditions. The conditions of EM are of different widths of masking on the edge. SC refers to a lower density of water jets on cooling zone than intensive cooling (IC). PC means that the set water cooling zone at posterior of the ROT is different with anterior cooling (AC). Initial transverse temperature difference (ITTD) implies the temperature difference on transverse of the steel strip. Every condition of the methods is compared with the FE model to determine the best conditions. The detailed conditions of the methods are shown in Table 2.

In Table 2, the conditions in the column of condition 2 are boundary conditions of the BM. The conditions of the EM refer to the width of the masking from the edge of the steel strip. The SC is the abbreviation of sparse cooling. Compared with intensive cooling, the SC has less water flow and the cooling is more uniform. The PC is the abbreviation of the posterior cooling, and the PC means the cooling water is opened at the back section of the ROT. The conditions of the ITTD refer to the temperature difference between the strip edge and the middle part. 


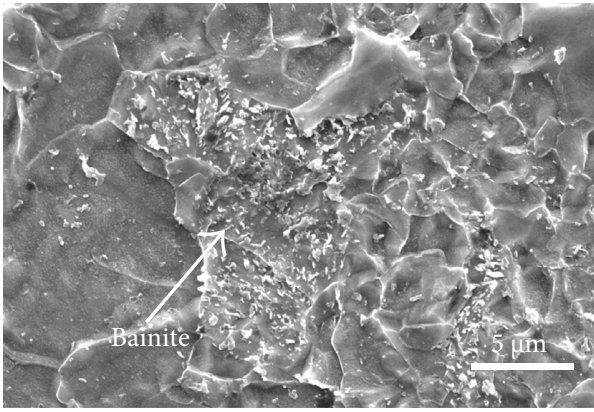

(a)

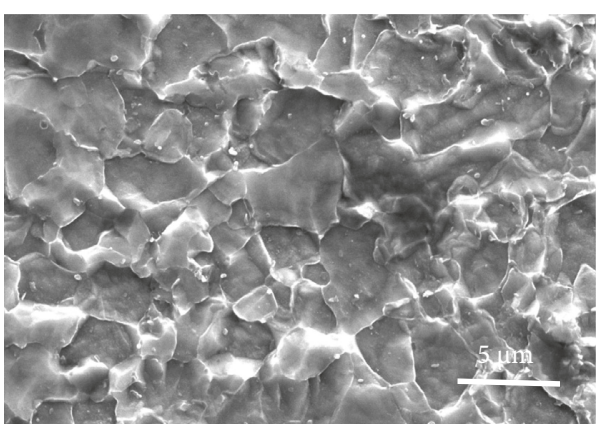

(b)

FIGURE 19: SEM images: (a) edge of the strip; (b) middle of the strip.

3.2.1. Edge Masking. EM is thought to be an effective process for reducing residual stress on the ROT. It needs to install an extra device on the ROT to shelter the cooling water nozzles above or below the edge of the strip. Two other FE models corresponding to different widths of masking were established based on the BM. The comparison of the stress distribution from the three FE models is shown in Figure 22.

The cooling water stays on the upper surface and flows to the edge when it reaches the upper surface of the strip. Therefore, more water is on the edge than the central part, thereby increasing the heterogeneity of temperature. The EM technology aims to block the water from shooting to the edge of the strip and decrease the water volume on edge, thus reducing the cooling rate of the edge. Furthermore, this technology can reduce the heterogeneity of temperature and phase transformation on the strip. As a result, the deformation on edges and central part tends to be more synchronous, thereby reducing the residual stress of the strip.

After cooling, the distribution forms of residual stress of the FE models are the same, where a small tensile stress exists on the central section and large compressive stress occurs on the edges. The stress on the edge is reduced by $33.20 \mathrm{MPa}$ when the width of EM is $0.2 \mathrm{~m}$ compared to no EM. However, it increases by $26.68 \mathrm{MPa}$ when the width of edge masking is $0.3 \mathrm{~m}$. If the width of edge masking is too large, the nonsynchronization of cooling on steel strips would be more significant and the thermal stress would be great. Hence, the width of EM should be appropriately determined according to the width of steel strips.

3.2.2. Sparse Cooling. SC means decreasing the density of the cooling water by closing part of the pipe nozzles of the laminar cooling system. It is an effective method to improve the homogeneity of cooling. A FE model corresponding to SC is established to analyze the effect of SC in comparison with the BM. The effect of SC is shown in Figure 23.

The SC technology aims to lower the cooling rate by reducing the volume of water. The difficulty of controlling the cooling process is reduced, and heat conduction plays a more important role when the cooling rate is kept low. As

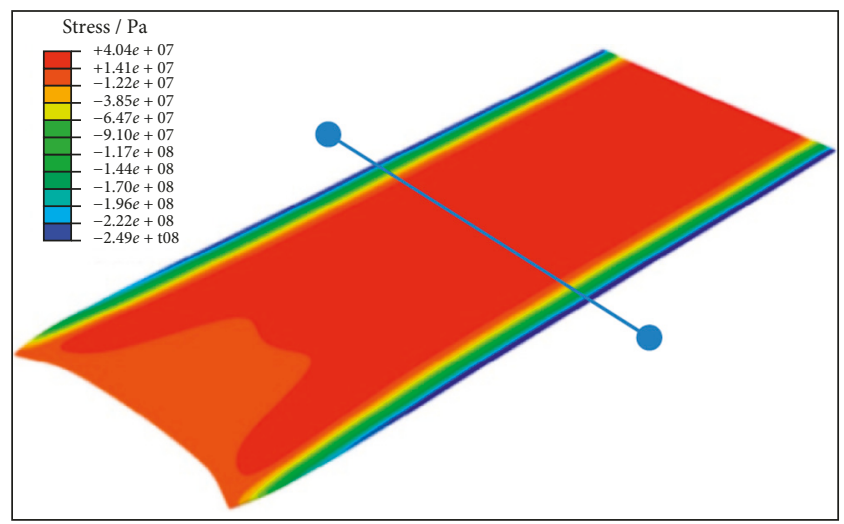

Figure 20: Contour of stress distribution.

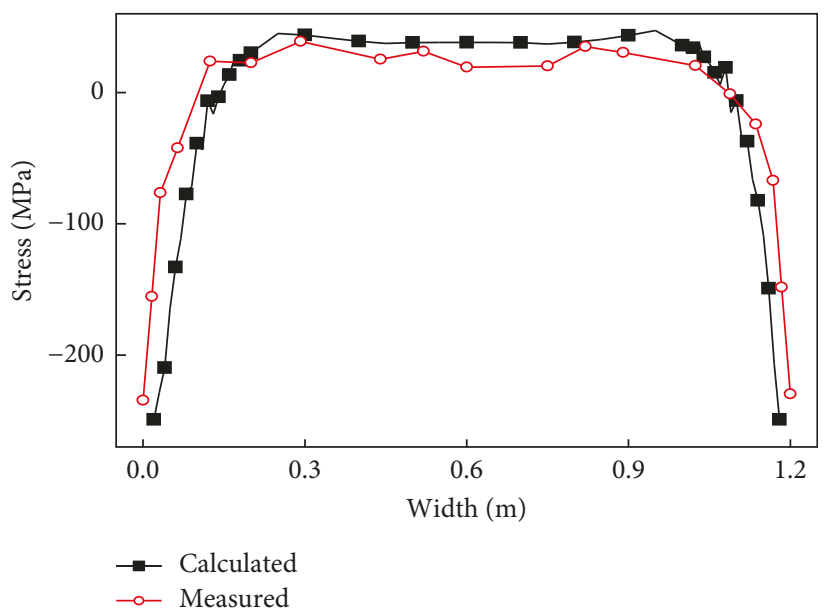

FIGURE 21: Stress distribution on the transverse direction.

a result, the heterogeneity of temperature and phase transformation is reduced, and the deformation on the edge and central parts tends to be more synchronous, thereby reducing the residual stress of strip.

The results of stress distribution from the two FE models after cooling show that the distribution forms of residual stress are the same. The stress on the edge is reduced by 45.2 $\mathrm{MPa}$ when SC is applied. The results show that SC has noticeable effect on reducing residual stress. 
TABLE 2: The detailed conditions of the methods.

\begin{tabular}{lccc}
\hline Methods & Condition 1 & Condition 2 & Condition 3 \\
\hline EM & $0.2 \mathrm{~m}$ & $0 \mathrm{~m}$ & $0.3 \mathrm{~m}$ \\
SC & SC & IC & - \\
PC & PC & AC & - \\
ITTD & $30^{\circ} \mathrm{C}$ & $60^{\circ} \mathrm{C}$ & $90^{\circ} \mathrm{C}$ \\
\hline
\end{tabular}

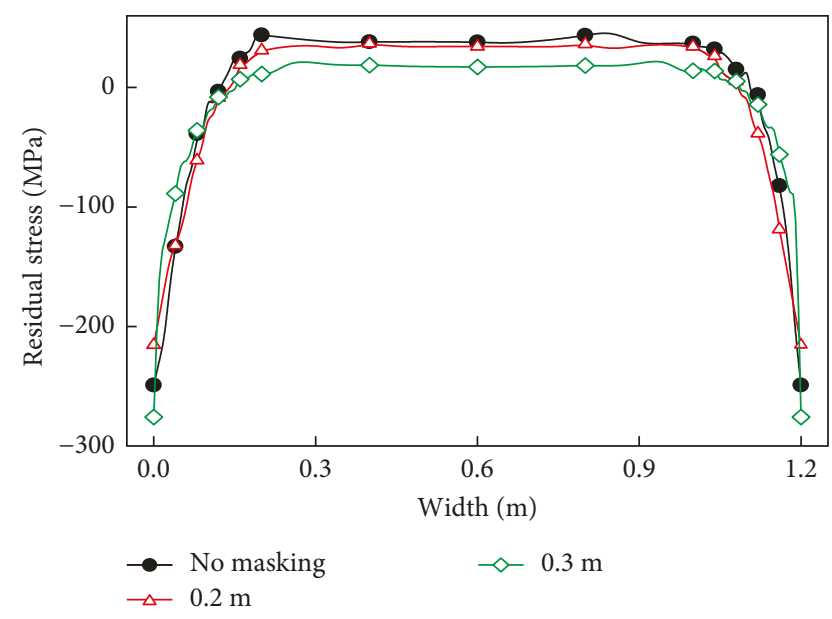

FIgURE 22: Effect of edge masking.

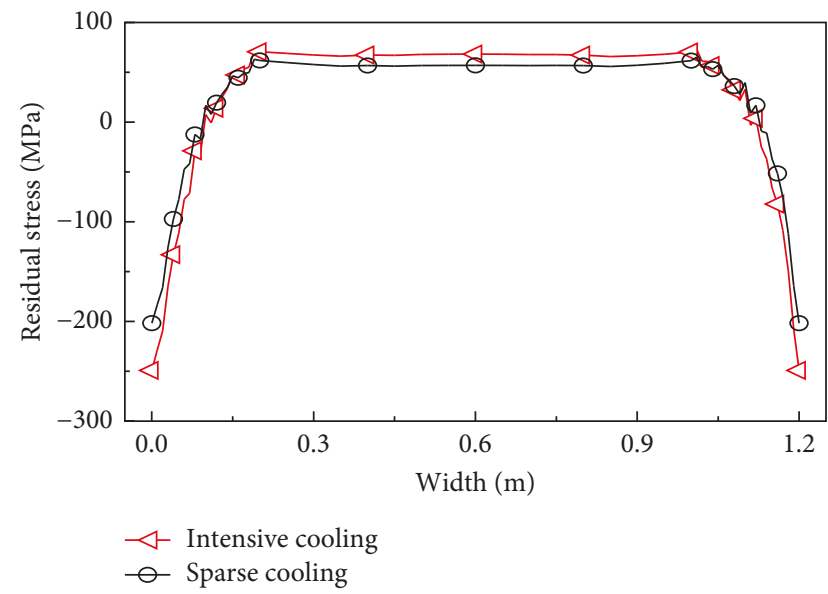

FIgURE 23: Effect of sparse cooling.

3.2.3. Posterior Cooling. PC refers to the position of the water-cooling zone on the posterior of the ROT. While a FE model is established to analyze the effect of this method, the BM corresponds to the AC in Figure 24. The results of these two models are compared, as is shown in Figure 24.

When the PC technology is applied, the cooling rate is low when the strip is on the forepart of the ROT and the temperature on strip tends to be homogeneous with the effect of heat conduction. Therefore, the phase transformation and deformation on different parts of the strip are homogeneous at the water-cooling zone, which reduce the residual stress.

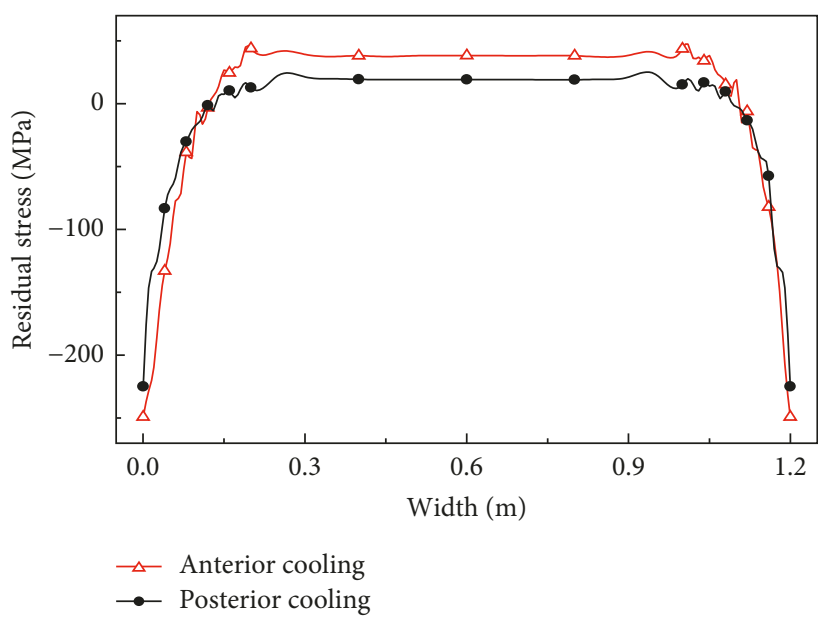

FIGURE 24: Effect of posterior cooling.

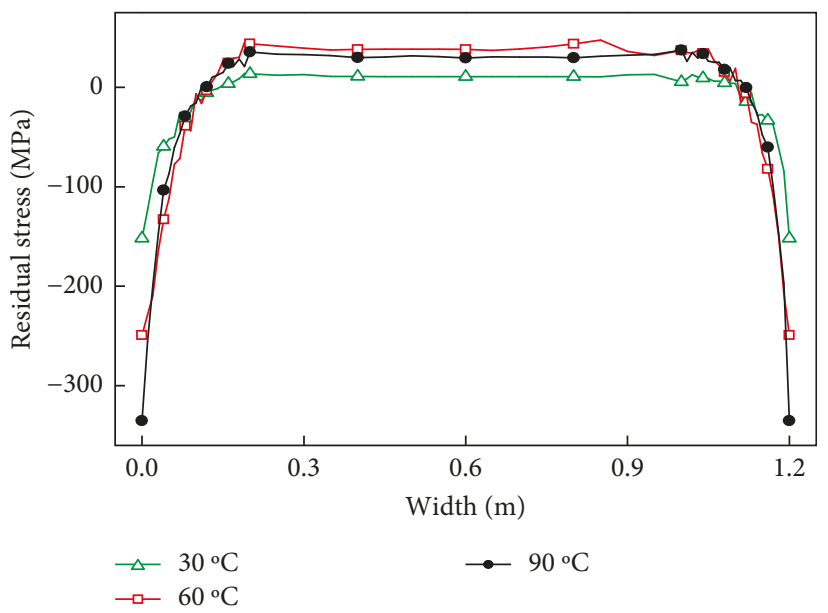

FIgURE 25: Effect of initial transverse temperature difference.

TABle 3: Comparison of the methods.

\begin{tabular}{lccc}
\hline Methods & Best conditions & Reduction (MPa) & Percent \\
\hline EM & $0.2 \mathrm{~m}$ & 33.20 & 13.59 \\
SC & SC & 45.22 & 18.15 \\
PC & PC & 24.24 & 9.73 \\
ITTD & $30^{\circ} \mathrm{C}$ & 97.29 & 39.05 \\
\hline
\end{tabular}

The residual stress on the edge reduces by $24.24 \mathrm{MPa}$ when PC is applied. The temperature distribution of the strip tends to be uniform because of heat conduction before the strip enters the water-cooling zone. The method of PC can reduce the stress of steel strips (Figure 24).

3.2.4. Initial Transverse Temperature Difference. The temperature difference causes the difference in thermal expansion, which is the origin of thermal stress. Moreover, the temperature difference causes the nonsynchronization of phase transformation on different parts of the steel strip. The 
initial transverse temperature difference influences the stress distribution of the steel strips. In this research, the temperature difference of the FE models is set to 30,60 , and $90^{\circ} \mathrm{C}$, whereas the temperature difference of the $\mathrm{BM}$ is $60^{\circ} \mathrm{C}$. The results of the FE models are shown in Figure 25.

The residual stress on the edge reduces by $97.29 \mathrm{MPa}$ when the initial transverse temperature difference is $30^{\circ} \mathrm{C}$; however, it increases by $86.03 \mathrm{MPa}$ when the initial transverse temperature difference is $90^{\circ} \mathrm{C}$. Hence, the initial transverse temperature difference has a great influence on reducing residual stress.

3.2.5. Comparison of the Four Methods. According to the calculation results, all of the four methods can reduce the residual stress of the steel strip. The quantitative analysis on the effect of the methods is shown in Table 3.

Based on the results, the best method for reducing residual stress is by reducing the initial transverse temperature difference before the strip enters the ROT. The quantitative comparison of methods showed that the effect of the methods on reducing residual stress ranks as follows (descending order): reducing the ITTD of the steel strip, the SC, the EM, and the PC.

\section{Conclusion}

A three-dimensional FE model of a high-strength low-alloy steel strip on the ROT was established in this research to simulate the coupled processes of thermal, phase transformation, and stress. It was named as basic model. Several experiments and tests were performed to verify the precision of the BM. Several FE models were built based on the BM to quantitatively analyze the effect of the four methods. Several conclusions can be summed up from this research as follows:

(1) The phase transformation products in the strip during cooling are ferrite and bainite on the edge but only ferrite on the central section. The different cooling rates and initial temperatures cause these differences.

(2) The distribution of the residual stress on the transverse of the steel strip after cooling is compressive stress on the edge and tension on the central section. Thus, the flatness of the steel strip tends to develop edge waviness according to shape theory.

(3) The effect of the four methods on reducing residual stress ranks follows the order (descending): reducing the ITTD of the steel strip, the SC, the EM, and the PC.

\section{Conflicts of Interest}

The authors declare that there are no conflicts of interest regarding the publication of this paper.

\section{Acknowledgments}

The authors would like to express their thanks for funding provided by National Natural Science Funds of China (51404021) and Beijing Municipal Natural Science Foundation (3154035).

\section{References}

[1] F. Qi, D. F. Zhang, X.H. Zhang, and X. Xu, "Effects of Mn addition and $\mathrm{X}$-phase on the microstructure and mechanical properties of high-strength $\mathrm{Mg}-\mathrm{Zn}-\mathrm{Y}-\mathrm{Mn}$ alloys," Materials Science and Engineering A, vol. 593, pp. 70-78, 2014.

[2] J. Fatemeh, A. Heidarpour, X. L Zhao et al., "Application of high strength and ultra-high strength steel tubes in long hybrid compressive members: experimental and numerical investigation," Thin-Walled Structures, vol. 102, pp. 273-285, 2016.

[3] S. K. Maity, A. K. Rajak, M. C. Shekhar, and S. D. Singh, "Development of ultra high strength steel by electroslag refining and thermomechanical treatment," Transactions of the Indian Institute of Metals, vol. 69, no. 3, pp. 705-716, 2016.

[4] Z. W. Peng, L. J. Li, J. X. Gao, and X. Huo, "Precipitation strengthening of titanium microalloyed high-strength steel plates with isothermal treatment," Materials Science and Engineering A, vol. 657, pp. 413-421, 2016.

[5] R. K. Kumar, S. K. Sinha, and A. K. Eahiri, "Modelling of the cooling process on the runout table of a hot strip milla parallel approach," Industry Applications IEEE Transactions, vol. 33, no. 3, pp. 807-814, 1997.

[6] M. M. Prieto, L. S. Ruíz, and J. A. Menéndez, “Thermal performance of numerical model of hot strip mill runout table," Ironmaking and Steelmaking, vol. 28, no. 6, pp. 474480, 2001.

[7] H. N. Han and S. H. Park, "Model for cooling and phase transformation behaviour of transformation induced plasticity steel on runout table in hot strip mill," Materials Science and Technology, vol. 17, no. 6, pp. 721-726, 2013.

[8] J. Hrabovský, M. Pohanka, P. J. Lee, and J. H. Kang, "Experimental and numerical study of hot-steel-plate flatness," Materiali in Tehnologije, vol. 50, no. 1, pp. 17-21, 2016.

[9] X. D. Wang, Q. Yang, and A. R. He, "Calculation of thermal stress affecting strip flatness change during run-out table cooling in hot steel strip rolling," Journal of Materials Processing Technology, vol. 207, no. 1-3, pp. 130-146, 2008.

[10] A. Milenin, P. Kustra, R. Kuziak, and M. Pietrzyk, "Model of residual stresses in hot-rolled sheets with taking into account relaxation process and phase transformation," Procedia Engineering, vol. 81, pp. 108-113, 2014.

[11] H. H. Cho, Y. G. Cho, D. W. Kim, S. J. Kim, W. B. Lee, and H. N. Han, "Finite element investigation for edge wave prediction in hot rolled steel during run out table cooling," ISIJ International, vol. 54, no. 7, pp. 1646-1652, 2014.

[12] Z. D. Liu, D. Fraser, I. V. Samarasekera, and G. T. Lockhart, "Experimental observations and modelling of thermal history within a steel plate during waterjet impingement," Canadian Metallurgical Quarterly, vol. 41, no. 1, pp. 75-86, 2002.

[13] N. L. Chester, M. A. Wells, and V. Prodanovic, "Effect of inclination angle and flow rate on the heat transfer during bottom jet cooling of a steel plate," Journal of Heat Transfer, vol. 134, no. 12, p. 122201, 2012.

[14] GB/T228.1-2010, Method of Tensile Test for Metallic Materials [S].

[15] X. D. Wang, Research on Influencing Mechanisms of Laminar Cooling on Flatness of Hot Rolled Steel Strip and Related Control Strategy [D], University of Science and Technology Beijing, Beijing, China, 2007.

[16] X. D. Wang, F. Li, Q. Yang, and A. R. He, "FEM analysis for residual stress prediction in hot rolled steel strip during the run-out table cooling," Applied Mathematical Modelling, vol. 37, no. 1-2, pp. 586-609, 2013. 
[17] Y. P. Su, Research on Internal Stress and Buckling During Laminar Cooling of Hot Rolled Steel Strip [D], University of Science and Technology Beijing, Beijing, China, 2009.

[18] F. Dong, The Research of Flatness of Hot-Rolled Strip on RunOut Table [D], Yanshan University, Qinhuangdao, China, 2014.

[19] Z. Y. Liu, Simulation and Prediction of the Evolution of Microstructure and Properties of Hot Rolled Steels [M], Northeast University Press, Boston, MA, USA, 2004.

[20] P. R. Chappidi, F. S. Gunnerson, and K. O. Pasamehmetoglu, "A simple forced convection film boiling model," International Communications in Heat and Mass Transfer, vol. 17, no. 3, pp. 259-270, 1990.

[21] Z. Cai, "Research on buckling behavior of hot-rolled strip after cooling," Ph.D. Dissertation, Northeastern University, Boston, MA, USA, 1998.

[22] E. B. Hawbolt, B. Chau, and J. K. Brimacombe, "Kinetics of austenite-ferrite and austenite-pearlite transformations in a 1025 carbon steel," Metallurgical and Materials Transactions A, vol. 16, no. 4, pp. 565-578, 1985.

[23] H. H. Choa, Y. G. Choa, Y. R. Imb et al., "A finite element analysis for asymmetric contraction after coiling of hot-rolled steel," Journal of Materials Processing Technology, vol. 210, no. 6, pp. 907-913, 2010.

[24] H. N. Han, J. K. Lee, D.-W. Suh, and S.-J. Kim, "Diffusioncontrolled transformation plasticity of steel under externally applied stress," Philosophical Magazine, vol. 87, no. 1, pp. 159-176, 2007. 


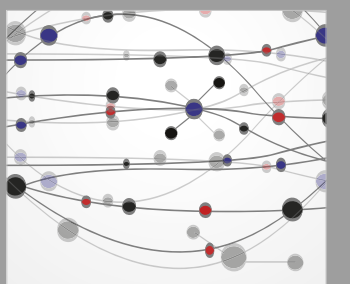

The Scientific World Journal
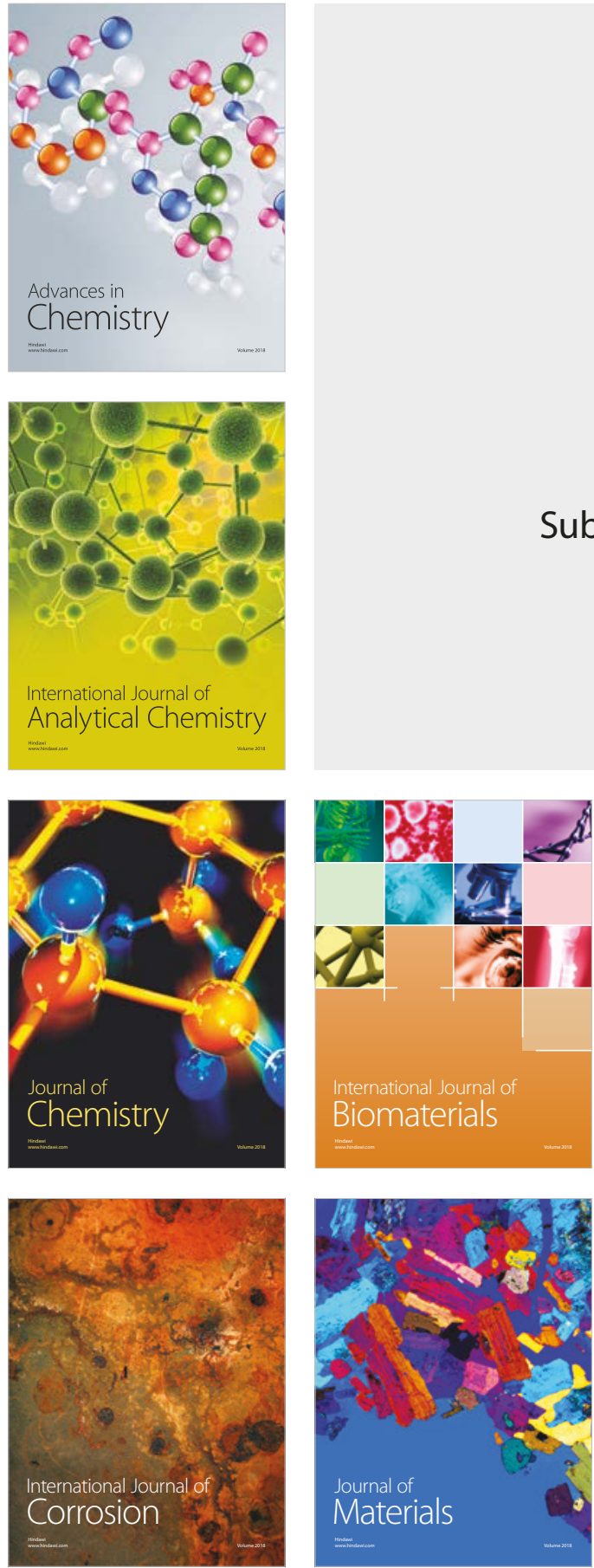

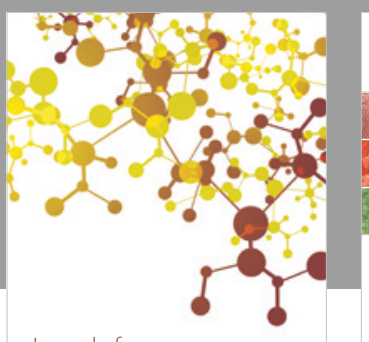

Journal of

Applied Chemistry
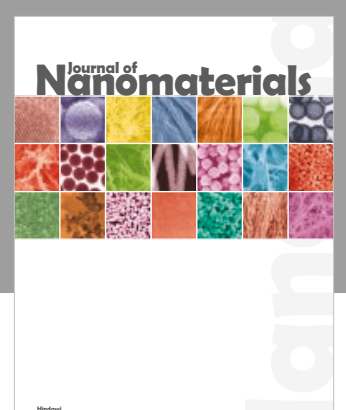

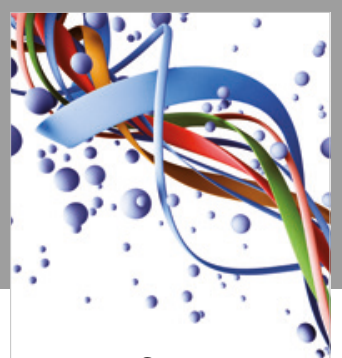

Scientifica

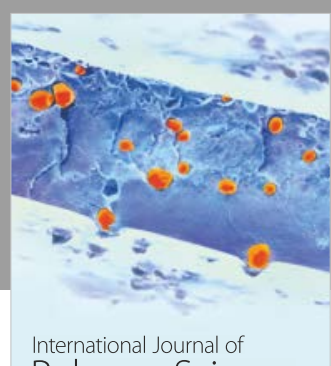

Polymer Science

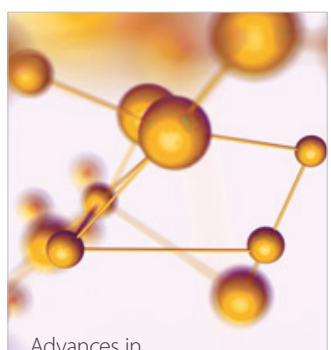

Physical Chemistry
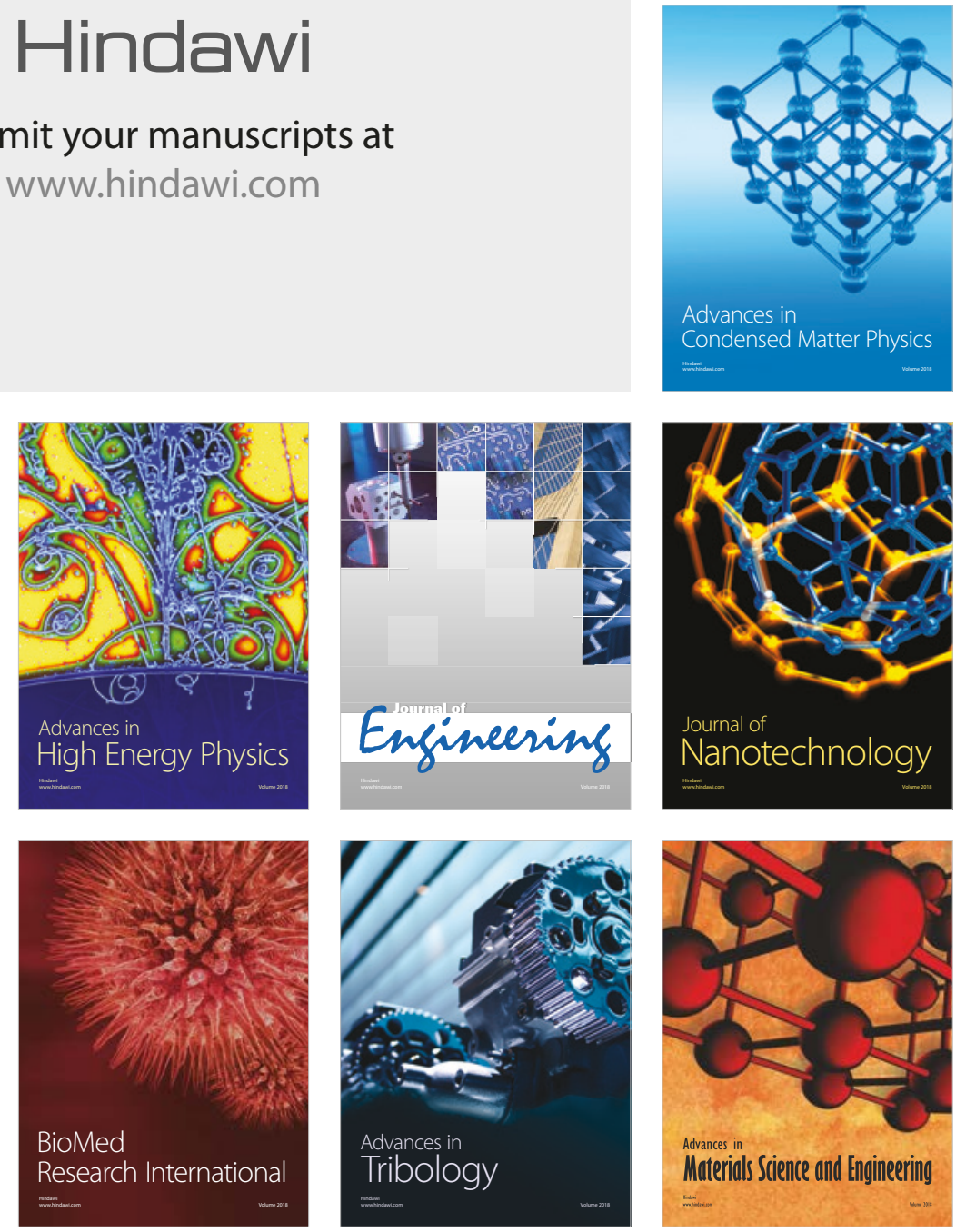